Prostat Biyopsisi Yapılan Hastalarda Beden Kitle İndeksinin Ağrı Skorları Üzerine Olan Etkisi

\title{
The Effect of Body Mass Index on Pain Scores in Patients Who Underwent Prostate Biopsy
}

Deniz Bolat, Mehmet Erhan Aydın, Tansu Değirmenci, Yusuf Kadir Topçu, Özgü Aydoğdu, İbrahim Halil Bozkurt, Tarık Yonguç

Bozyaka Eğitim ve Araştırma Hastanesi, Üroloji Kliniği, İzmir, Türkiye

\section{$\ddot{O Z E T}$}

GİRIŞ ve AMAÇ: Bu çalışmada TRUS-PBx'deki ağrı skorları ile hastaların beden kitle indeksleri (BKI) arasındaki ilişki araştırlmışıtır.

YÖNTEM ve GEREÇLER: Ekim 2014-Nisan 2015 arasında anormal parmakla rektal muayene bulgusu ve/veya yüksek prostat spesifik antijen (PSA) düzeyi $(\geq 2,5 \mathrm{ng} / \mathrm{ml})$ nedeniyle TRUS-PBx yapılan toplam 198 hasta çalışmaya dâhil edildi. Biyopsi öncesinde tüm hastalara $10 \mathrm{ml} \% 2$ prilokainle transperineal periprostatik sinir blokajı uygulandı. A $\breve{g r}$ r skorları 10’luk lineer vizüel analog skala (VAS) kullanılarak, ultrason probu rektuma yerleştirildikten hemen sonra (VAS-1) ve biyopsi esnasında iğne girişi sırasında (VAS-2) ă̆rı düzeyi değerlendirildi. BKI'ye göre hastalar 2 gruba ayrlldılar: Grup-1 ( $n=156) B K \dot{I}<30 \mathrm{~kg} / \mathrm{m} 2$ olan hastalarl, grup-2 $(n=42)$ $B K I \geq 30 \mathrm{~kg} / \mathrm{m} 2$ olan hastalart içermekteydi.

BULGULAR: Hastaların ortalama yaşı $64 \pm 7.3$ yll ve ortalama PSA değeri $12.5 \pm 18.3 \mathrm{ng} /$ dl idi. Prostat kanseri tespit oranı \%22.7 idi. Grup-1'deki hastalarin VAS-1 skoru grup-

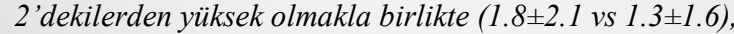
aradaki fark istatistiksel olarak anlamlı değildi $(p=0.123)$.

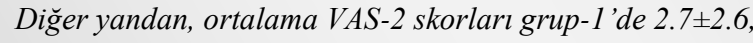
grup-2'de $1.9 \pm 1.7$ idi ve aradaki fark istatistiksel olarak anlamliyd $(p=0.026)$.

TARTIŞMA ve SONUÇ: BKİ düsük olan hastalar TRUS-PBx işleminde prostat örneklemesi sirasında daha fazla ă̆rı hissetmektedirler. Bu hastaların konforunu artırmak için alternatif anestezi teknikleri göz önünde bulundurulmalıdır.

Anahtar Kelimeler: Prostat biyopsisi, lokal anestezi, beden kitle indeksi, ağrl, obezite

\section{Iletişim / Correspondence:}

Dr. Deniz BOLAT

Bozyaka Eğitim ve Araştırma Hastanesi, Üroloji Kliniği, İzmir, Türkiye E-mail: drbolat@hotmail.com

Başvuru Tarihi: 14.07.2016

Kabul Tarihi: 10.11.2016

\section{ABSTRACT}

INTRODUCTION: In this study we assessed the relationship between pain scores during transrectal ultrasound-guided prostate biopsy (TRUS-PBX) and body mass index (BMI) of the patients.

MATERIAL and METHOD: Between October 2014-April 2015, 198 patients who underwent prostate biopsy with abnormal digital rectal examination findings and/or high PSA levels $(\geq 2,5 \mathrm{ng} / \mathrm{ml})$ were included in this study. Before the biopsy procedure, all patients underwent transperineal periprostatic block with $10 \mathrm{~mL}$ of $2 \%$ prilocaine. A 10-point linear visual analogue scale (VAS) was used to assess the pain arising from probe insertion (VAS-1) and prostate sampling (VAS-2). According to BMI, patients were divided into 2 groups: Group-1 $(n=156)$ included BMI $<30 \mathrm{~kg} / \mathrm{m} 2$ and Group$2(\mathrm{n}=42)$ included $B M I \geq 30 \mathrm{~kg} / \mathrm{m} 2$.

RESULTS: The mean age of the patients was $64 \pm 7.3$ years, and the mean PSA value was $12.5 \pm 18.3 \mathrm{ng} / \mathrm{dl}$. Prostate cancer detection rate was $22.7 \%$. VAS-1 score was higher in group-1 than group-2 (1.8 $2.1 \mathrm{vs} 1.3 \pm 1.6)$, however, the difference was not statistically significant $(p=0.123)$. The mean VAS-2 scores were $2.7 \pm 2.6$ in group-1 and $1.9 \pm 1.7$ in group -2 and the difference was statistically significant $(p=0.026)$.

DISCUSSION AND CONCLUSION: Patients with a low BMI feel more pain at the time of prostate sampling during TRUS$P B x$. In these patients alternative anesthesia techniques can be considered in order to increase the patients' comfort.

Keywords: Prostate biopsy, local anesthesia, body mass index, pain, obesity 


\section{GIRIȘ}

Transrektal ultrason kilavuzluğunda yapılan prostat biyopsisi (TRUS-PBx) prostat kanseri tanis1 koymak için standart yöntemdir $(1,2)$. Amerika Birleşik Devletleri'nde yılda yaklaşık 1 milyonun üzerinde prostat biyopsisi yapıldığı tahmin edilmektedir (3). Ağrı bu işlemin en önemli handikaplarından birisidir. Son yıllarda daha genç yaştaki hastalara prostat biyopsisi yapılması, daha çok sayıda kadrandan biyopsi alınması ve tekrarlayan prostat biyopsiler nedeniyle ağr1 kontrolünün önemi artmıştır. İlk olarak biyopsi öncesi hastanın anksiyetesini mümkün olduğunca azaltmaya çalışmak ve hastayı bilgilendirmek gereklidir (4). Aksi takdirde, şiddetli ağrıya bağlı olarak, işlemin hasta tarafından tolerabilitesi düşmekte ve bu durum planlanan kor sayısında azalmaya ve kanser tespit oranlarında düşüşe neden olabilmektedir (5). Bu nedenle TRUS-PBx'de ağn kontrolünün sağlanması ve hasta toleransının artrılması son derece önemlidir.

Prostat biyopsisi sırasında ağrıyı azaltmak amacıyla çeşitli analjezi ve anestezi yöntemleri geliştirilse de, periprostatik sinir blokajı günümüzde en sık kullanılan ve altın standart yöntemdir (6). Buna alternatif olarak geliştirilen transperineal periprostatik sinir blokaj1 da, özellikle anorektal patolojisi olan hastalarda uygulanabilecek güvenli ve etkili bir yöntemdir (7). Yapılan çalışmalarda hasta yaşının, alınan kor sayısının ve kor lokalizasyonunun, prostat hacminin ve işlem sirasindaki hasta pozisyonunun TRUS-PBx sırasında hissedilen ağrı üzerine olan etkileri değerlendirilmiştir (8-10).

Günümüzün önemli bir sağlık sorunu olan obezitenin bazı operasyonları teknik olarak zorlaştırdığı, obez hastaların operasyonlarının zayıf hastalara kıyasla daha uzun sürdüğü ve daha fazla lokal anesteziye ihtiyaç duyulduğu bildirilmiştir (11). Fakat prostat biyopsisi yapilan obezlerin ağrıyı zayıf kişilere kıyasla ne derecede hissettikleri bilinmemektedir. Bu çalışmada TRUS PBx yapılan hastalarda, BKİ'nin işlem sırasında hissedilen ağrı üzerine olan etkisi değerlendirilmiştir.

\section{GEREÇ ve YÖNTEM}

Ekim 2014 ile Nisan 2015 tarihleri arasında kliniğimizde prostat spesifik antijen (PSA) yüksekliği $(\geq 2,5 \mathrm{ng} / \mathrm{ml})$ olması ve/veya parmakla rektal incelemede prostatında şüpheli lezyon tespit edilmesi üzerine ilk kez TRUS-PBx yapılan toplam 198 hasta çalışmaya dâhil edildi. Hastalar anamnez, PSA, fizik muayene ile değerlendirildi. Tüm hastaların işlem öncesi boy ve vücut ağırlıkları ölçülerek beden kitle indeksleri (BMİ=kilo/boy2) hesapland. BKI $<30 \mathrm{~kg} / \mathrm{m} 2$ olanlar grup 1'e, $\geq 30$ $\mathrm{kg} / \mathrm{m} 2$ olanlar grup 2'ye dahil edildiler. Bu çalışma Bozyaka Eğitim ve Araştırma Hastanesi Etik Kurulu tarafından onaylanmış, Helsinki Deklerasyonu Prensipleri'ne uygun olarak yürütülmüş ve çalışmaya dahil edilen tüm hastalardan bilgilendirilmiş onam alınmıştır.

Prostat biyopsisi öyküsü olan, herhangi bir nörolojik hastalığı olan, kronik pelvik ağr sendromu olan, bilinen üriner ya da genital malignensisi olan, kanama diyatezi olan ve aktif üriner sistem enfeksiyonu olan hastalar çalışmaya dahil edilmemişlerdir.

Hastalara işlemden önce ve işlem sonrası 3 gün kullanmak üzere florokinolon profilaksisi verildi ve barsak temizliği olarak işlem günü rektal lavman uyguland1. Tüm hastalara biyopsi öncesinde $10 \mathrm{ml}$ $\% 2$ prilokainle parmak kılavuzluğunda transperineal periprostatik sinir blokaj1 uyguland 1 (7). Biyopsi işlemi $18 \mathrm{G}$ Trucut $^{\mathrm{TM}}$ iğne ile 12-16 kor şeklinde otomatik biyopsi tabancası kullanılarak yapild1.

Transperineal periprostatik sinir blokajı tekniği: Hastaya dorsal litotomi pozisyonu verildikten sonra perineal alan antiseptik solüsyon ile temizlenir. Hasta kendi eliyle skrotumunu perineden yukarıya doğru kaldırır. Biyopsi işlemini yapacak olan kişi sol elinin işaret parmağını anal kanaldan içeri sokar. $\mathrm{Bu}$ parmağın kılavuzluğu eşliğinde $27 \mathrm{G}$ iğne ile prostatın sağ lobunun tabanına doğru, rektumun $1.5-2 \mathrm{~cm}$ yukarısından orta hat çizgisi ile 30 derece açı olacak şekilde perineden girilir ve transperineal cilt ve subkutan doku geçilerek prostata ulaşılır. İntravasküler enjeksiyondan kaçınmak amaciyla enjektörle aspirasyon yapılır. Eğer enjektöre kan geldiği gözlenmezse, iğne prostatın bazisinden apexine doğru hafifçe geriye doğru çekilirken $5 \mathrm{~mL}$ anestezik ajan periprostatik alana enjekte edilir. Enjekte edilen anestezik ajan, anal kanaldaki sol elin işaret parmağının ucu ile, prostat yüzeyinde bombeleşme olarak hissedilir. Aynı işlem iğne 
perineal ciltten çıkarılmaksızın sol taraf için de uygulanır. Ardından sistematik prostat biyopsisi işlemine geçilir.

Ağr1 skorlar1 10'luk lineer vizüel analog skala (VAS) kullanilarak, ultrason probu rektuma yerleştirildikten hemen sonra (VAS-1) ve biyopsi esnasında iğne girişi sırasında (VAS-2) ağrı düzeyi değerlendirildi. VAS skorunda 0 ağrısız (veya hiç rahatsızlık duymadım) olarak skorlandırılırken, 10 dayanılmaz ağrı (veya dayanılmaz rahatsızlık) olarak belirlendi.

\section{İstatistiksel Analiz}

Veriler Statistical Package for Social Sciences (SPSS, version 17.0 for Windows, Chicago, IL, USA) programı ile analiz edildi ve değişkenin tipine göre ortalama \pm standard sapma, sayı ve yüzde olarak verildi. İki grup arasında sayısal verilerin karşılaştırılması için bağımsız gruplar $T$ testi, kategorik verilerin karşılaştırılması için kikare testi kullanıldı. $\mathrm{P}<0.05$ değerler istatistiksel olarak anlamlı kabul edildi.

\section{BULGULAR}

Çalışmaya katılan hastaların yaş ortalamaları 64 $\pm 7,3$ (43-83), ortalama PSA değerleri 12,5 $\pm 18,3$ $(0,6-142) \mathrm{ng} / \mathrm{dl}$ idi. Prostat kanseri tespit oran1 \%22.7 olarak bulundu (Tablo 1).

Çalışmaya dahil edilen hastaların patoloji sonuçları değerlendirildiğinde; 60'ında $\quad(\% 30,3)$ benign prostat hiperplazisi (BPH), 52'sinde $(\% 26,3)$ kronik prostatit, 24'ünde $(\% 12,1)$ prostatik intraepitelyal neoplazi (PİN), 11 'inde $(\% 5,5)$ atipik küçük asiner proliferasyon (ASAP), 45'inde $(\% 22,7)$ prostat adenokarsinomu ve 6 'sinda (\%3.1) PİN+kronik prostatit tespit edildi (Tablo 1).

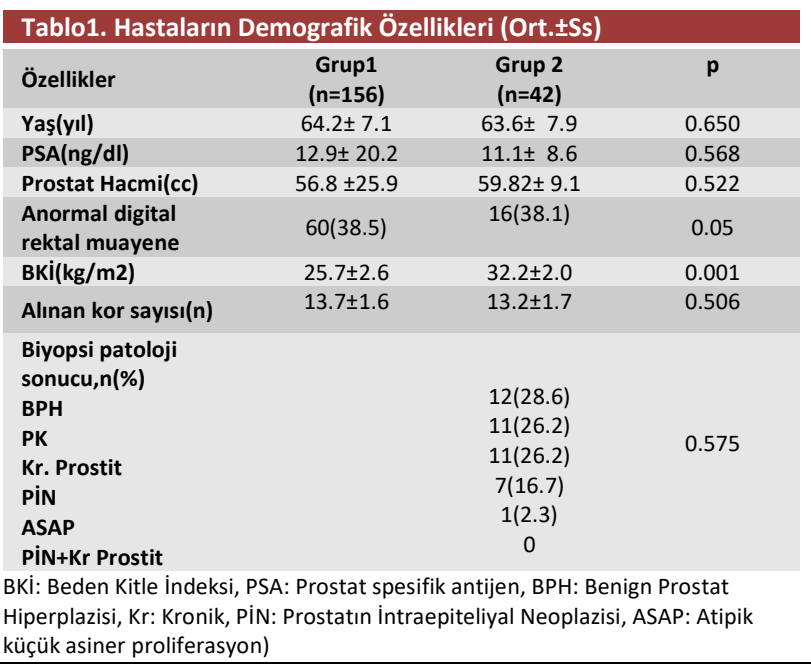

Çalışmaya dahil edilen hastaların ortalama BKI değeri $38,1 \pm 27,1 \mathrm{~kg} / \mathrm{m} 2$ idi. Hastalardan 156 'sının BKİ değeri $<30 \mathrm{~kg} / \mathrm{m} 2$ iken 42 'sininki $\geq 30 \mathrm{~kg} / \mathrm{m} 2$ idi.

Hastaların VAS-1 ortalamaları karş1laştırıldığında, Grup 1'de 1,8 \pm 2,1 ve Grup2 'de $1,3 \pm 1,6$ idi $(p=0,123)$. VAS-2 değerleri ise Grup 1 ve 2 için sırasıyla; $2,7 \pm 2,6$ ve $1,9 \pm 1,7$ idi $(\mathrm{p}=0,026)$ (Tablo 2).

\begin{tabular}{|c|c|c|c|}
\hline & $\begin{array}{c}\text { Grup1 } \\
(n=173)\end{array}$ & $\begin{array}{l}\text { Grup2 } \\
(n=25)\end{array}$ & p \\
\hline VAS-1 & $1.7 \pm 2.0$ & $1.7 \pm 1.8$ & 0.957 \\
\hline VAS-2 & $2.6 \pm 2.4$ & $2.0 \pm 2.3$ & 0.290 \\
\hline
\end{tabular}

VAS:Vizüel Analog Skala

\section{TARTIŞMA}

Transrektal ultrason kılavuzluğunda yapılan prostat biyopsisi prostat kanseri tanısinda kullanılan standart yöntemdir. İşlem sırasında hissedilen ağrı hasta konforunu etkileyen önemli bir sorundur. Ağrı temelde iki nedene bağlı olarak ortaya çıkmaktadır: birincisi prob girişine ve manüplasyonuna bağl1 oluşan anal rahatsızlık, ikincisi ise prostat kapsülünden iğne geçişi esnasında hissedilen ağnı (12)

İlk kez Nash ve arkadaşları tarafından geliştirilen periprostatik sinir blokajı, ağrının azaltılmasında iyi bir seçenek olmuştur. Bu blokajda anestezik ajan prostat tabanı ve seminal vezikül bileşkesine enjekte edilmektedir. Günümüzde bu teknik, TRUS-PBx yapilacak olan hastalarda standart hale gelmiştir (13). Biz bu çalışmada, anestezi tekniği olarak, kendi geliştirmiş olduğumuz transperineal periprostatik sinir blokajını uyguladık (7). Bu yöntemin avantajı, prob girişi esnasındaki ağrının kontrolünde periprostatik sinir blokajı ile rektal jel kombinasyonu tekniğine göre daha etkili olmasıdır.

Çalışmamızın sonuçlarına göre, transperineal periprostatik sinir blokaj1 altındaki TRUS-PBx yapılan hastalarda kanser tespit oranımız \%22.7 olarak bulunmuştur. Her ne kadar bu çalışmada ortalama PSA değeri yüksek olsa da $(12.5 \pm 18,3$ ng/dl), kanser tespit oranımızın düşük olmasının sebebinin biyopsi işleminin farklı tecrübelerdeki ürologlar ve patolojik incelemelerin farklı tecrübelerdeki patologlar tarafindan yapılıyor olmasından kaynaklandığı düşüncesindeyiz. 
Transrektal ultrason kılavuzluğunda yapılan prostat biyopsisi sırasında hissedilen ağriya etki eden faktörlerin araştırıldığı çalışmalarda, Bastide ve arkadaşları (14) hiçbir anestezi tekniği uygulamadan gerçekleştirdikleri TRUS-PBx işleminde yaş, prostat volümü, alınan kor sayısı, operatör, önceki biyopsi öyküsü ve ilk kor lokalizasyonunun ağr1 üzerine olan etkisi değerlendirilmişlerdir. Bu çalışmanın sonucunda bu 6 faktör içerisinden yalnızca ilk kor lokalizasyonun (ilk apex biyopsisi) ağrı üzerine etkili olduğunu bildirmişlerdir. Gomez ve arkadaşları (15) posterolateral sinir paketine lokal anestezi uyguladıktan sonra yaptıkları TRUS-PBx işleminde, yaş, önceden biyopsi öyküsü varlığı, prostat hacmi ve ağrılı rektal muayene bulgusunun işlem sırasında hissedilen ağrı için bağımsız risk faktörü olduğunu bildirmişlerdir. Moussa ve arkadaşları (16) ise transrektal prob dizaynının ve iğne kılavuzunun TRUS-PBx işleminin her etabında ağrı üzerine etkili olduğunu göstermişlerdir. Bolat ve arkadaşlarının yaptıkları çalışmalarda ise işlem sırasında hissedilen ağrı ile daha önceden biyopsi öyküsü olması veya biyopsi patoloji sonucu arasında ilişki olmadığı gösterilmiştir $(17,18)$. Biz bu çalışmamızda BKİ'nin biyopsi sırasındaki ağrı skorları üzerine olan etkisini değerlendirdik. Bildiğimiz kadariyla, literatürde bu konuda yapılmış başka bir araştırma bulunmamaktadır. Çalışmamızın sonuçlarına göre, prob girişi esnasında hissedilen ağrı (VAS 1) BKİ $<30 \mathrm{~kg} / \mathrm{m} 2$ olan hastalarda diğerlerine kıyasla benzer düzeyde bulunurken, örnekleme sirasında hissedilen ağrı $\mathrm{BKI}<30 \mathrm{~kg} / \mathrm{m} 2$ olan hastalarda anlamlı olarak daha yüksek bulunmuştur. Khimich (19) 18-84 yaş aras1 sağlıklı kişilerin ağrıya duyarlıklarını araştırdığ çalışmasında şişman hastaların diğerlerine kıyasla daha yüksek ağrı duyarlılığına sahip olduğunu ve dolayısıyla da daha az ağrı hissettiklerini bildirmiştir. Panni ve Columb (20) gebeler üzerinde yaptıkları çalışmada obez gebelerin doğum sırasında daha az epidural lokal anestezik maddeye ihtiyaç duyduklarını göstermişlerdir. Buna karşılık, obez hastalarda ultrason k1lavuzluğunda yapılan interskalen sinir blokajının daha zorlu olduğunu ve analjezinin yetersiz olduğunu gösterilmiştir (21). Bir başka çalışmada ise, lokal anestezi altında ambulatuvar herni cerrahisi uygulanan hastalarda ağr1 intraoperatif ağrı skorlarının obezlerde daha yüksek olduğu bulunmuştur (11).

Sonuç olarak, transperineal periprostatik sinir blokajı altında yapılan TRUS-PBx işlemi sırasında zayıf hastalar örnekleme işlemi sırasında daha fazla ağrı duymaktadırlar. $\mathrm{Bu}$ hastalarda transperineal periprostatik sinir blokaj1 yapılırken daha fazla anestezik ajan kullanılması gerekebileceği gibi hasta konforunu artırmak için alternatif anestezi teknikleri de göz önünde bulundurulmalıdır.

\section{KAYNAKLAR}

1.Hodge KK, McNeal JE, Stamey TA. Ultrasound guided transrectal core biopsies of the palpably abnormal prostate. J Urol 1989; 142:66-70.

2.Hodge KK, McNeal JE, Terris MK, et al. Random systematic versus directed ultrasound guided transrectal core biopsies of the prostate. J Urol $1989 ; 142: 71-4$.

3.Bostwick DG, Meiers I. Prostate biopsy and optimization of cancer yield. Eur Urol 2006; 49:415-7.

4.Acar C, Eskiçorapçı S, Bolat D. Prostat biyopsisi. Endoüroloji Bülteni 2010; 12:16-20.

5.Giannarini G, Autorino R, Valent $F$, et al. Combination of perianal-1ntrarectal lidocaineprilocaine cream and periprostatic nerve block for pain control during transrectal ultrasound guided prostate biopsy: a randomized, controlled trial. J Urol 2009; 181:585-93.

6.Heidenreich A, Bastian PJ, Bellmunt J, et al. EAU guidelines on prostate cancer. part 1: screening, diagnosis, and local treatment with curative intentupdate 2013. Eur Urol 2014;65:124-137.

7.Bolat D, Degirmenci T, Gunlusoy B, et al. Comparison of transperineal prostatic and periprostatic nerve blockage combined with rectal gel techniques for transrectal ultrasound-guided prostate biopsy and evaluation of pain scores in patients with concomitant anorectal pathologies. Eur Urol Suppl 2016;15: 1171-2.

8.Djavan B, Waldert M, Zlotta A, et al. Safety and morbidity of first and repeat transrectal ultrasound guided prostate needle biopsies: results of a prospective European prostate cancer detection study. J Urol 2001; 166:856-60. 
9.Rodríguez LV, Terris MK. Risks and complications of transrectal ultrasound guided prostate needle biopsy: a prospective study and review of the literature. J Urol 1998; 160:2115-20.

10.Kilciler M, Demir E, Bedir S, et al. Pain scores and early complications of transrectal ultrasonography-guided prostate biopsy: effect of patient position. Urol Int 2007; 79:361-3.

11.Acevedo A, Leo'n J. Ambulatory hernia surgery under local anesthesia is feasible and safe in obese patients. Hernia 2010; 14:57-62.

12.Otunctemur A,Dursun $\mathrm{M}$, Besiroglu $\mathrm{H}$, et al. The effectivity of periprostatic nerve blockade for the pain control during transrectal ultrasound guided prostate biopsy. Arch Ital Urol Androl 2013; 85:69-72.

13.Nash PA, Bruce JE, Indudhara $R$, et al. Transrectal ultrasound guided prostatic nevre blockade eases systemic needle biopsy of the prostate. J Urol 1996; 155:607-9.

14.Bastide C, Lechevallier E, Eghazarian C, et al. Tolerance of pain during transrectal ultrasoundguided biopsy of the prostate: risk factors. Prostate Cancer Prostatic Dis 2003; 6:239-41.

15. Gómez-Gómez E, Ramírez M, Gómez-Ferrer A, et al. Assessment and clinical factors associated with pain in patients undergoing transrectal prostate biopsy. Actas Urol Esp 2015; 39:414-9.

16. Moussa AS, El-Shafei A, Diaz E, et al. Identification of the variables associated with pain during transrectal ultrasonography-guided prostate biopsy in the era of periprostatic nerve block: the role of transrectal probe configuration. BJU Int 2013; 111:1281-6.

17.Bolat D, Aydin ME, Gunlusoy B, et al. Do the pain scores during prostate biopsy change in patients with a prior history of prostate biopsy? Eur Urol Suppl 2016; 15:1183.

18.Bolat D, Aydin ME, Degirmenci T, et al. Is there a relationship between the pain scores and pathology results of transrectal-ultrasound guided prostate biopsy? Eur Urol Suppl 2016; 15:1182.

19.Khimich S. Level of sensitivity of pain in patients with obesity. Acta Chir Hung 1997;36:1667.
20.Panni MK, Columb MO. Obese parturients have lower epidural local anaesthetic requirements for analgesia in labour. Br J Anaesth 2006; 96:106-10.

21.Schroeder K, Andrei AC, Furlong MJ, et al. The perioperative effect of increased body mass index on peripheral nerve blockade: an analysis of 528 ultrasound guided interscalene blocks. Rev Bras Anestesiol 2012; 62:28-38. 